contained playing with the rolling belt $(26.26 \%)$, too long hair or skirt (16.36\%), tread for power cut or other reasons $(4.26 \%)$. Accident area concentrated near the entrance or exit of escalator $(88.37 \%)$ and only 5 happened in the middle of the stairway following a tread (11.63\%).

Conclusions Escalator-related injuries to preschoolers damaged seriously in Guangdong Province, China. Better design for this electric equipment, adequate attention and safety education from families, and reasonable labels or notices around the site, are multilateral intervention approaches. They might help.

\section{A CASE OF LEAD POISONING TO AN ACTION OF BLOOD LEAD LEVEL SCREENING IN CHILDREN IN KRATUMBAN, THAILAND}

Chatchai Im-arom, Athipat Athipongarporn, Adisak Plitponkarnpim. Mahidol University, Bangkok, Thailand

\subsection{6/injuryprev-2016-042156.610}

Background Lead has known as the heavy metal which could be harmful to several human organs such as brain, bone marrow and kidneys. In 2012, an 8 month-old girl was admitted to PICU due to status epilepticus and has been diagnosed with Lead Poisoning with the Blood Lead Level (BLL) of $166 \mathrm{mcg} / \mathrm{dL}$. Then we conducted the field investigation and also checked the BLL of students and children living nearby who might have been at risk of poisoning.

Methods The sample of clothes, floor mat, tap water, dust and wall-paint in the room were collected and tested for Lead level, including the "earth" from the "big bag" which has been stored in the recycled-warehouse where the index case lived.

Three Primary Schools and 2 Child Centres which locate within the distance of $10 \mathrm{~km}$ from the index case were selected and divided into two groups; group A consists of 2 Schools and 1 Child Centre located around $3 \mathrm{~km}$ from the warehouse and group B consists of 1 School and 1 Child Centre which located 9 $\mathrm{km}$ away. Students and children with total number of 234 (222 children, 12 adults) were performed the BLL test and those whose the result of BLL is equal or higher than $10 \mathrm{mcg} / \mathrm{dL}$ will be classified as "High BLL" and those whose the result of BLL is lower than $10 \mathrm{mcg} / \mathrm{dL}$ will be classified as "Non-high BLL".

Results The high level of Lead was found in the sample from the girl's clothes and floor mat, and also extremely high in the "earth" from "big bag".

BLL test revealed 68 out of 234 (29.05\%) participants has been categorised as High BLL. Schools and Child Centres in group A which located nearer to the index case has higher percentage of students and children with high BLL comparing to group B (19.8\%-14.1\%).

Conclusions The Lead contamination in the index case could be from several sources. High BLL Students and children who live in Kratumban district is common. Further field investigation should be conducted to identify the source of contamination and BLL should be performed in every school in this area.

\section{SAFE KIDS @ HOME-A SURVEY ON CHINESE FAMILIES' PERSPECTIVES ON INDOOR AIR QUALITY AT HOME}

Fannie Wang, Roger Zhang, Mulder Wang, Lisa Li, Lydia Lu, Monica Cui. Safe Kids China, Honeywell China

10.1136/injuryprev-2016-042156.611
Background WHO put air pollution is one of the largest environmental risks, but people are more concerned about Outdoor Air Quality (OAQ) but little about Indoor Air Quality (IAQ). People's indoor activities accounts $70 \%$ to $90 \%$ time of a day. Children may stay longer. This survey is to learn Chinese families perspectives on IAQ, identify knowledge and behaviour gap and collect insights on IAQ promotion.

Methods 10 cities were selected based on geography and year average PM2.5. 100 school-aged children's families participated the survey in each city. Data from 1000 school-aged children was collected through school teachers. Children marked their choices on the questionnaire sheets while teacher reading the questions and choices. Data from 1000 parents was collected online. Parents got an survey invitation with online survey links, they completed the online survey and returned a signed feedback slip to school teacher.

Results $80 \%$ of the families consider OAQ as "worse". A limited knowledge of PM 2.5 and its impact, such as 31\% of kids have NEVER heard about the word PM 2.5 and 54\% of parent do not know the "safety level" of indoor PM 2.5 by WHO. Chemicals, bacteria and viruses are the most concerned ingredients on IAQ at home. An obvious gap between knowing and doing, such as smoking was rated as No. 1 bad for IAQ at home (72\%), but $58 \%$ of the parents were observed smoking at home. High consensus on improving IAQ at home with $87 \%$ families supporting actions on No Smoking, Ventilation, Green-materials for decoration and More greenery.

Conclusions The awareness on IAQ low while the need on IAQ is high. An obvious gap between knowing and doing on smoking at home. Great opportunities to conduct IAQ at home with majority families' support especially actions on No Smoking, Ventilation, Green-materials for decoration and more Greenery.

\section{THE EFFECT OF HOUSEHOLD SIZE ON INJURY RISK FACTORS IN SOUTHERN BRAZIL}

${ }^{1}$ Nicole Toomey, ${ }^{1}$ Deena El-Gabri, ${ }^{1,2}$ João Ricardo Vissoci, ${ }^{1,3}$ Catherine Staton. ${ }^{1}$ Duke Global Health Institute; ${ }^{2}$ Faculdade Ingá; ${ }^{3}$ Duke University Medical Centre

\subsection{6/injuryprev-2016-042156.612}

Background The neighbourhood an individual lives in affects their injury risk. In Brazil, males of minority races with low education have the highest risk for injury. Family is an important aspect of Brazilian culture; however there is little research on how family structure affects injury risk. This preliminary analysis investigates the association between household size and risk for types of injuries.

Methods Information on household demographics was collected in a survey on treatment-seeking behaviour following injury in Maringá, Brazil between May and September 2015. The prevalence of demographic factors, including insurance status, mode of transportation to health care, and education level, as well as reasons for not seeking care, were analysed by three categories of household size: 2 or fewer individuals, 3 to 5 individuals, and 6 or more individuals. Frequencies, range, and odds ratios were reported.

Results Of 2678 households, the mean household size was 3.39 (r 1-15). As household size increased, enrollment in private insurance decreased; $50.5 \%$ of households of 2 or fewer had private insurance compared to only $27.5 \%$ with 6 or more. Alcohol usage prior to injury increased with household size; $5.3 \%$ of individuals in households of 2 or fewer reporting use, compared and 
9.8\% in houses of 6 or more. Large households had higher odds of unspecified injuries (OR: 1.85), including acts of violence, compared to households with 5 or fewer members. Odds of burn decreased with household size increase (OR: 0.833).

Conclusions Household size is a component of socioeconomic status; our data shows it is associated with insurance and alcohol usage. Risk of certain injuries is associated with household size. Further research needs to assess where these injuries are occurring, such as work or home. More in-depth research is also needed on how household size affects the family member occupations, as this places them at higher risks for different forms of injuries.

\section{PRELIMINARY REPORT OF THE CINCINNATI HOME INJURY PREVENTION AND LITERACY PROMOTION TRIAL: INJURY HAZARD REDUCTION}

Kieran J Phelan, Bin Huang, Chen Chen, Stacey Liddy, Robert Ammerman, Bruce P Lanphear.

10.1136/injuryprev-2016-042156.613

Background Injury in the home is a leading cause of morbidity and mortality for US children.

Objective Test the efficacy of the installation of safety measures on injury hazard reduction in homes of high-risk mothers and infants.

Methods Of the 1,589 mothers referred by the Every Child Succeeds home visitation program, 650 (41\%) were eligible. Block randomization was used to assign households to the safety product installation intervention or control group. At the baseline home visit (BHV), a survey of 4 rooms (kitchen, main activity room, child's bathroom and bedroom) was conducted using a validated instrument. Inter-rater reliability of research assistant assessment of hazards was undertaken on a random sample of 100 homes. The number and density (number of hazards per 100 sq. ft.) of hazards were quantified at baseline, 12- and 24-month follow-up visits. Statistical analysis included Pearson correlation, analysis of variance, and Kappa statistics.

Results We randomly assigned homes of mother-child dyads to experimental, $(\mathrm{N}=324)$ or control $(\mathrm{N}=326)$ groups. Most homes were single story (60\%) and had a mean of 958 sq.ft. (s.d. 529) and 9 rooms (s.d. 3); 238 were single family (37\%), 276 were apartments (43\%) and the remainder multi-family homes (21\%).

Inter-rater reliability for the mean number and density of injury hazards was 0.81 and 0.93 respectively, for the 4-rooms assessed within hours of each other. For individual hazards, kappa scores ranged from 0.69 for visible sharps on accessible surfaces $<1$ metre from the floor to 0.96 for fire escape ladders available and accessible on $2^{\text {nd }}$ floor, and 0.99 slats of infant cribs $>0.6 \mathrm{~cm}$ apart.

At the BHV there were no significant differences in the mean number $(\mathrm{p}=0.28)$ or density of injury hazards $(\mathrm{p}=0.31)$ by group assignment. At the 12- and 24-month follow-up there were significant differences in the number $(p<0.001)$ and density $(\mathrm{p}<0.002)$ of injury hazards by group assignment. In the intervention arm, the mean number of hazards for the 4-room sample was reduced from 41.8 (95\% CI: 41.0, 42.6) to 33.6 (95\% CI: 32.7, 34.6) at 12-months $(\mathrm{p}<0.001)$ and $32.5(95 \%$ CI: $31.5,33.5)$ at 24 -month home visit $(\mathrm{p}<0.001)$.

Conclusions An intervention to reduce exposure to injury hazards in the homes of low-income mothers and their infants recruited from a home visitation program significantly reduced the number and density of injury hazards through 24-months of follow-up.

\section{CAN USERS' OPINIONS HELP TO IMPROVE TRAFFIC CALMING INTERVENTIONS?}

${ }^{1}$ Andres Gugliotta, ${ }^{2}$ Petya Ventsislavova, ${ }^{1}$ Pedro Garcia-Fernandez, ${ }^{1} J o s e$ Luis Padilla, ${ }^{3}$ Tim Horberry, ${ }^{1}$ Candida Castro. 'University of Granada, Spain; ${ }^{2}$ Nottingham Trent University, UK; ${ }^{3}$ Monash University Accident Research Centre, Australia

\subsection{6/injuryprev-2016-042156.614}

Background Traffic calming interventions attempt to reduce accidents, improve mobility of users and enhance the liveability of the local environment. Speed limit reductions and adaptation of the infrastructure are some actions frequently implemented. Results of these types of interventions can be explored by analysing users' opinions, such as their needs and preferences before, during and after the intervention.

Methods A survey was performed to explore the effects on infrastructure remodelling of the Cartuja Campus at the University of Granada in Spain. Habits, opinions and attitudes from a total population of 21,892 users were collected. A total of 393 users from a stratified random sample took part in this study. The user groups included were: "residents on campus", "workers of nearby shops", "students", "teaching and research staff”, "administration and service workers", and "parents and teachers of a school located on the campus". A questionnaire was used to collect the users' opinions in four basic areas: mobility, environment, safety and informing users about the objectives of the engineering works.

Results Results found that the following issues were considered to be very important and necessary for the user: an improvement of fluidity and functionality of public transport, accessibility to the campus for both pedestrians and vehicles, perceived road safety conditions and usability of the campus. However, users considered themselves to be poorly or not informed regarding the aims, planning and developing of the engineering works, and during the implementation of works, $22.1 \%$ of them reported to have changed their mean of transportation as a result of that engineering activity. The key groups affected by the changes were students, campus workers and users of the school.

Conclusions This current survey, taking place during the engineering interventions, will subsequently serve as baseline for the second phase once the infrastructure remodelling work in completed. In particular it will analyse the impact on mobility of the Campus Cartuja remodelling, evaluate the success of the "traffic calming" measures, and investigate if healthy mobility has been successfully encouraged. From these combined results, implications about road design and planning will be derived, as well as additional suggestions for improving traffic calming: these will be reported back to the infrastructure designers and used to further refine the infrastructure changes.

\section{BUILT ENVIRONMENT AROUND HIGH SCHOOLS IN GALLE, SRI LANKA: AN OBSERVATORY STUDY}

${ }^{1,2}$ Enying Gong, ${ }^{3}$ Vijitha De Silva, ${ }^{3}$ Hemajith Tharindra, ${ }^{1}$ Catherine Staton. ${ }^{1}$ Duke University, US; ${ }^{2}$ Duke Kunshan University, China; ${ }^{3}$ Ruhuna University, Sri Lanka

10.1136/injuryprev-2016-042156.615 